\title{
The Curriculum of Cybercrime and Computer Forensics for Liberal Arts Majors
}

\author{
Ling Tang \\ Dept. Information Science and Technology, Criminalistics School \\ East China University of Political Science and Law \\ Shanghai, China, 201620 \\ E-mail: ausflug163@163.com
}

\begin{abstract}
At present, cybercrime has become a serious phenomenon. It not only leads to the harm for the society, but also leads to the challenge for the academic circle. So it is very important for the university to develop a related curriculum and train students to deal with it. East China University of Political Science and Law has set up a curriculum named as cyber-crime and computer forensics for eight years. Usually, the students who are liberal arts majors are short of computer science knowledge. The author overcomes the difficulty and gets great achievement. Thus, the curriculum has been supported by the university as the undergraduate construction course in 2016. The teaching experience will be written in the teaching material in 2018.
\end{abstract}

Keywords-computer forensics; cybercrime; curriculum; liberal arts majors

\section{INTRODUCTION}

In the information time, people cannot live and work without computer technology and cyber service. Nevertheless, cybercrime has become a serious phenomenon. In 2016, 154 million American voters' data were leaked; 117 million LinkedIn (LED) users' data were also sold in the dark network, etc. [1]. At the same time, China has also turned into a cybercrime victim nation. According to the national Internet Emergency Center (CNCERT/CC) data statistics, from January to November in 2016, the number of web sites which had been tampered has achieved the amount of 62894. Among this number, there were 1483 websites belonging to government websites [2]

All in all, cybercrime has not only been a serious threat to the privacy of citizens and business interests, but also threatened national security and society fortune. So it is very important to combat cybercrime and maintain Internet security. That leads to a new research point for academic circle: cybercrime and computer forensics.

Many universities and research institutes have studied the cybercrime and computer forensics for many years. However, they usually divide the problem in two independent sides, one is researched from the point of information security problem; and the other one is researched from the point of legal issues.

As a matter of fact, cybercrime and computer forensics are the puzzles combined with computer science and law issues. It is better to regard the puzzles as an interdisciplinary rather than two different sides. East China University of Political Science

This work is supported by National Important Social Science Foundation of China (No. 14ZDB147) and Law (ECUPL) is one of the top law schools in China. In 2005, the department of computer science was established depending on the strong legal background of ECUPL. And it is necessary to set up a curriculum to focus on cybercrime and computer forensics for the college students who major in computer science. In 2007, a curriculum called information crime and computer forensics has been set up. In 2013, it has been honored as an important curriculum from Shanghai Municipal Education Commission.

Based on these great achievements, in 2009, an elective public curriculum for all of the students in ECUPL was set up. The curriculum is named as cybercrime and computer forensics. The most difficult part for the teacher is how to teach the frontier discipline towards liberal arts majors who are lack of computer science knowledge.

The author is the teacher of the curriculum and also one of the writers of the teaching material. The author has accomplished the work very successfully and finished the research project named as the undergraduate course construction of ECUPL in 2016.

\section{DEFINITION OF COMPUTER FORENSICS}

According to the research of the foreign computer forensics experts, Judd Robbins who is a senior expert, put forward the definition of computer forensics like this: it is put into practice in the investigation of computer and analysis technique. It is applied to the confirmation and the obtainment of the evidence which is potential and legally effective [3]. CERT and NTI extend the definition; it includes the protection, the confirmation, the extraction, the filing of the computer evidence which is stored the way of magnetic medium coding information.

According to the research of China academic circle, the definition of computer forensics is described as the following part: computer forensics is crucial to the combat cybercrime. It is a process which can be accepted by the court, can be reliable enough, can be convincing enough. And the process exists in the computer and the related the peripheral. What's more, the process also contains the confirmation, the collection, the protection, the analysis, the filing and the court presentation of the electronic evidence [4].

Other experts consider that computer forensics is a process can confirm, protect, extract and file electronic evidence which 
exists in computer and related peripherals, and can make it acceptable and reliable by court [5].

\section{The Evaluation of CyBercrime}

With the review of history, the cyber has developed from Internet 1.0 to Internet 2.0, Internet 3.0, and Internet 4.0. Nowadays, a new phrase called Internet+ has appeared in the newspapers, in the social media, and even in the government work report. This is a new challenge to the cybercrime. It is characteristic of the amalgamation of three kinds of network.

That is to say, the telecommunication network, the broadcast television network and the computer communication network have combined into one network. The substantive analysis is that the network has turned from information service into content service. It does not only bring the convenience to the people the entire world, but also bring the cybercrime to the people the entire world. One of the dilemmas of the cybercrime is that during the expanding of computer terminal and network, the criminal evaluation is becoming more and more difficult. The other one is that morphological variation of accomplice leads to the vacuum of the criminal evaluation [6].

Statistics suggest that the victimization probability shows geometric growth. It is an urgent duty for the judicial authority to expand the legislative ideas. In most cases, the cybercrime does not create a new type of crime; it only changes the old crime form with the help of computer science and Internet.

\section{THE CURRICUlum OF CYBER CRIME AND COMPUTER FORENSICS}

This part introduces the curriculum itself. The achievement will be brought forth. The reason of its success will be discussed. The future of the curriculum will be planned.

\section{A. The foreign status of the curriculum}

This curriculum has been a new project for Universities. At the very beginning, it was named as computer forensics, which was only a supplement to information security major. In the recent years, several universities all over the world have begun to set up special computer forensics project and some research has started. Meanwhile, some research institutions also joined in this domain. For instance, Canterbury Christ Church University has established the research point for the master of Computer Forensics [7]. It carried out a lot of computer forensic measurement to sustain the criminal investigation relating to computer evidence. The project includes the practice and theory. So it is totally fit with those who are already engaged, or devote themselves to law enforcement or expert testimony in UK or elsewhere. As to the U.S.A., the center of security information system set up some related courses for the Master. California University has built the lab aim at information security and has started some related research work.

We can draw the conclusion that those foreign universities and research institutions mentioned above manage the course as a master curriculum or a research work. None of them set up the course for the undergraduate students. It is not only a pity for the college students, but also not suit with the status of cybercrime.

\section{B. The curriculum in ECUPL}

In China, cybercrime and computer forensics curriculum is only established for the professional police universities or founded as a complementary class for traditional information security colleges. In 2015, cyber space security has been approved as a discipline by the Education Department. Up to now, there are 27 colleges and universities approved the introduction of a new network of space security doctoral degree or master degree. It is regret that none of the colleges or universities have set up a related course for undergraduate students.

ECUPL is a university which is famous of law school for more than sixty years. It is one of the first class legal universities in China. So undoubtedly, it owns abundant legal background. According to our investigation, many students in ECUPL are interested in cybercrime and computer forensics. In 2009, a curriculum called cybercrime and computer forensics has set up. Up to the present, it is lasted for eight years. It is satisfy with the needs of all the undergraduate students in ECUPL, especially those who are liberal arts majors and gets great teaching effect.

The curriculum is set up by the department of information science and technology, Criminalistics School. The Criminalistics School has begun forensic education and research for more than twenty years. So based on these academic background, we set up the curriculum as a character subject. It combines computer science and forensics technology even legal knowledge together, and interdisciplinary among each disciplines. We set the curriculum as a course with unique feature.

The students are from all of the majors in the university. Most of them come from legal school, business school, sociology school even from foreign language school. Considering their background and their focus are for extending their knowledge, so the difficulty of the computer science is reduced, the interest of the class is enhanced. Some information security knowledge even some skills to prevent their computers form hackers are taught in class. As to the professional experiments, they are demonstrated by the teacher instead of practicing by students.

From the students achievements and their evaluation of the class, we can see that the curriculum is not only qualified for the curriculum as a course with unique feature, but also can increase the knowledge of cybercrime and computer forensics for the students in ECUPL. Therefore, we can see that the curriculum achieved satisfactory teaching effect.

\section{The Curriculum in Detail}

In this part, the details of the curriculum will be presented. The achievement of the students will also been demonstrated. And the teaching material will be recommended. 


\section{A. The background of the curriculum}

The curriculum is considered as an elective public class which means that all of the students in ECUPL can take it as an elective course and get two credits. Up to now, it has been founded for eight years and 676 students are taught. It is one of the popular classes in ECUPL. The concrete number of students in every year is shown in Fig. 1. It should be pointed out that it seems that in 2009 and 2010, there are more than 100 students who took it as an elective course. And after that, there were about 70 students who took it as an elective class.

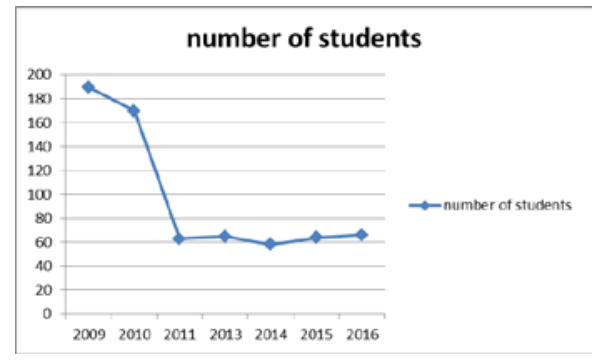

Fig. 1. Students number of the curriculum

In 2009 and 2010, there were two semesters which the curriculum was set up. And since 2011, there was only one semester which the curriculum was set up. So it is very naturally that the number of students was changed.

\section{B. The challenge of the curriculum}

The course includes information security, information crime, the invasion of computer, computer forensics, the collecting of electronic evidence, the recovery of electronic data, the analysis and evaluation of electronic evidence, the tools of computer forensics, and the introduction to some related laws. It covers the knowledge of information security, computer forensics, computer science, cybercrime, and procedural law.

As mentioned above, the students are major in liberal arts. That is to say, their knowledge of computer science is not professional, so it is very difficult for them to understand cybercrime and computer science.

In order to deal with the problem, the curriculum is set for 2 classes for each week. Compared with students who major in computer science, the class hour is decreased for 2 classes in every week. Considering the conflict with their professional classes, the course is arranged in the evening. And due to the students their knowledge of computer science is not professional, the difficulty is decreased. The assessment method of the class is more flexible. Most of the time, the exam is the demand of an article. As to the experiments, owing to their lack of computer science knowledge, the teacher demonstrates the experiments in lab instead of the traditional experiment manners. In this way, not only has the burden of the students been lightened, but also can learn through practice.

According to the statistics, the source of students comes from more than five schools. Most of the students (55\%) are from law school. It validates the character of the course: combining computer science with forensics and law issues. $25 \%$ of the students are from business school. With the development of electronic business, more and more business disputes or crimes involve electronic data, such as electronic signature, electronic accounting. This leads to the concern of computer forensics. It is a new challenge and requirement for forensic accounting. Nowadays, more and more experts have realized this problem. For example, in 2010, China University of Political Science and Law began to recruit the students major in electronic forensic accounting for Master Degree. In the ECUPL, some graduate students in business school also do some research in electronic forensic accounting. But as abovementioned in this paper, due to the students are lack of information crime and computer forensics education background in undergraduate period, they have difficulty in understanding this concept. So the elective course is a good introduction or complementarity for them. Thus, this explains the percent of business school in this course. $18 \%$ of the students are from intellectual property rights school. At present, with the popularity of computers and internet, many works, audio and video products are made from electronic form. So their copyrights are easily pirated and are difficult to be tracked. This situation results in the focus of computer forensics whether in cases or in research. Other students are from foreign language school, sociology school, etc. They choose this course because of interest. So they put great enthusiasm in learning this course. In the latter part of this paper, the author will explain why some students are good at their research work and bring out some innovation view in this field.

In conclusion, by the use of scientific teaching methods, the author succeeds in teaching the course.

\section{The achievement of the curriculum}

In 2013, the author has begun a research project with the name the undergraduate course construction of ECUPL. The focus is how to teach the liberal arts students. And in 2016, the project was accomplished.

At first, the author thinks that teaching in class does not simply mean imparting what is written in the book. It is also very important to train their capability to gain knowledge by themselves, to inspire their capability to discover new fields.

So the author is keeping on discovering pluralistic teaching mode. Through PPT and other multimedia courseware, the class becomes more interesting. In class, the teacher not only teaches the knowledge in book, but also combines the actual cases with professional technology. So the students can enhance their understanding of the knowledge. What's more, the teacher usually ask the students to suppose themselves as hackers or a computer forensics experts, and what would they do in the supposed scene and why they do so. As a result, not only the interactive between the teacher and the students is improved, but also the effect of the class is enhanced.

In order to train their innovation capability, 3 or 5 students constitute several research teams voluntarily. They are asked to do some research of information crime or computer forensics. The subject is chosen by themselves. At the end of the semester, each team should stand on the podium and demonstrate their research results. Their performance will impact their final scores. 
As to the students' performance, speaking of the passion, the class is more passionate than the computer science class. Although the students' research work is not very professional, their subjects are very innovative. For example, one team from sociology school studied the hacker phenomena, instead of focus on computer technology; they discussed it from the angle of view of culture, even raised to philosophical perspective. And their view is very innovative and reasonable. They won the applause for a long time and got A naturally.

The author thinks that it is because the students whom select the curriculum are really interested in this field, their research work are more innovative and most of them are based on their professional knowledge, such as law, sociology, business, etc. As a teacher, the author knows the interest is the best guider. So the students' performance $t$ is obvious.

Meanwhile, the teacher sets up the online class through internet. The students can communicate with the teacher after class. It is a very useful complement to the rational teaching method.

All in all, according to the above method, the atmosphere in class becomes active, the interest and effect of the students are inspired. The achievement is excellent naturally.

\section{The teaching material}

At first, we used a teaching material named "Internet Crime and Computer Forensics". But as time went on, we found that it was not fit for the class. With our research of the teaching material market, we drew the conclusion that none of the books meet our need. And based on our teaching experience, in 2009, our department and Dr. Qi Man in Canterbury Christ church university decided to wrote a teaching material by ourselves. The book is named as "Information Crime and Computer Forensics”, published by Beijing University Publishing House. The author wrote chapter five: the discovery and collecting of electronic evidence. The chapter is about 50,000 words. In September, 2010, the book is put into practice. Up to now, students from 4 grades have used it, and get satisfactory results. In 2011, the book is honored as the second prize of excellent teaching material of university in Shanghai 2011.

In 2017, we decide to publish the improved version of the book and what's more, a new book named as the supporting experiments material is planned. This work can improve the construction of teaching material and the quality of the class.

\section{OTHER RESEARCH WORK}

As a teacher, the author knows that research work is also an important work. It is well known that through research, the teacher can improve their professional quality, widen their knowledge. And put the research results into teaching, to further improve the quality of teaching.

By the end of 2016, the author has completed three research projects as the leader. One is a project to discover the computer forensics problems which lasted for 3 years. One is named as the National Social Science Foundation of China. Another is a research project about computer forensics supported by
ECUPL. The last one is supported by China Law Society, the research finding is published.

Besides these research projects, the author also focuses on education reform work. By the end of 2016, the author has completed three teaching projects as the leader. One is an important class of ECUPL. The other is a reform of teaching supported by ECUPL. And the last one is named as the undergraduate construction course of ECUPL in 2016.

Now, the author has been the member of one project. It is called as the National Important Social Science Foundation of China.

On the basis of these education and research experience, the author stared her own postdoctoral work in 2011. And in 2014 the author completed her own postdoctoral work.

\section{THE Future TEACHING WORK}

With the development of computer technology, new information crime comes out endlessly. So the computer forensics has to keep on developing. So the author needs improve the teaching work, summarize and optimize the experience of teaching. Enlarge the current teaching achievement, improve the quality of teaching. The concrete methods are the following:

(1) The teachers will keep on join in the training class to improve themselves. Pay close attention to the latest development of this discipline; make it useful in the teaching process. So the students can grasp the latest developments.

(2) The teachers should continue to organize the students to join in the related competition, to put their knowledge into practice and resolve the actual problems. It is complementary to the teaching in class.

(3) The teachers will use more flexible and more multiform way to examine the students. The aim of the exam is not for score but for the students to grasp the knowledge and comprehend the progress of the discipline. And improve the creativity and research capability.

\section{VIII.SUMMARY}

In this article, the author discusses the current situation of cybercrime and computer forensics and the construction of the curriculum. The author focuses on the challenge of the teaching toward the liberal arts majors. And the experience is displayed.

To make a long story short, cybercrime and computer forensics is a frontier interdisciplinary. It combines computer science with legal matters. The author wishes that more and more scholars and experts can join in the construction of this field.

\section{REFERENCES}

[1] URL: http://www.doit.com.cn/p/267913.html (In Chinese)

[2] URL: http://www.gold678.com/dy/A/755647 (In Chinese)

[3] Robbins, Judd. "An Explanation of Computer Forensics." URL: http://www.computerforensics.net/forensics.htm 
[4] Wang Yong Quan, Qi Man, The Information Crime and Computer Forensics, Beijing University Publishing house, 2010, pp.113-114. (In Chinese)

[5] Chen Long, Mai Yong Hao, Huang Chuan He, The Technology of Computer Forensics, Wuhan University Publishing house, 2007, pp.110. (In Chinese)

[6] Yu Zhi Gang,Yu Chong,The System and Development of CyberCrime, China Legal System Publishing house, 2013, pp.1-18. (In Chinese)

[7] Wang qingqing, The emergy response and computer forensics (2nd edition), QingHua University Publishing house, 2004, pp3-15. (In Chinese) 